\title{
3D culture enhances chemoresistance of ALL Jurkat cell line by increasing DDR1 expression
}

\author{
JUN GUO ${ }^{1,2^{*}}$, CHUNTING ZHAO ${ }^{3 *}$, RUYONG YAO $^{4}$, AIHUA SUI $^{4}$, LINGJIE SUN $^{3}$, XIAODAN LIU $^{3}$,

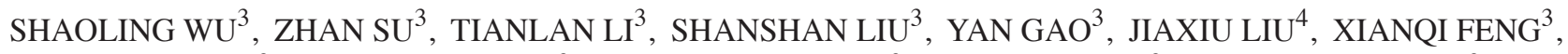 \\ WEI WANG ${ }^{3}, \mathrm{HONGGUO} \mathrm{ZHAO}^{3}, \mathrm{ZHONGGUANG} \mathrm{CUI}^{3}$, GUANGLUN $^{3}$ and FANJUN MENG ${ }^{3}$ \\ ${ }^{1}$ College of Medicine, Qingdao University, Qingdao, Shandong 266071; ${ }^{2}$ Department of Hematology, \\ People's Hospital of Rizhao, Rizhao, Shandong 276800; ${ }^{3}$ Department of Hematology, \\ Affiliated Hospital of Qingdao University, Qingdao, Shandong 266555; ${ }^{4}$ Central Laboratory, \\ Affiliated Hospital of Medical College, Qingdao University, Qingdao, Shandong 266035, P.R. China
}

Received May 24, 2018; Accepted November 30, 2018

DOI: 10.3892/etm.2019.7153

\begin{abstract}
Three dimensional (3D) culture has gradually become a research hotspot in the field of drug screening, stem cell research, and tissue engineering due to its more physiological-like morphology and function. In this study, we compared the differences of cell proliferation, population, protein expression and chemoresistance profiles between two dimensional (2D) and 3D culture of acute lymphoblastic leukemia (ALL) Jurkat cell line. Polycaprolactone (PCL) is used for 3D culture owing to its biochemical properties and compatibility. Culturing of ALL Jurkat cell line in collagen type I coated polycaprolactone scaffold for $168 \mathrm{~h}$ increased cell proliferation, attachment, as well as the drug resistance to cytarabine (Ara-C) and daunorubicin (DNR) without changing the original $\mathrm{CD} 2{ }^{+} \mathrm{CD} 33^{+} \mathrm{CD} 4^{+ \text {dim }} \mathrm{CD} 8{ }^{-} \mathrm{CD} 34^{-} \mathrm{CD} 45^{+ \text {dim }}$ phenotype, compared to uncoated PCL scaffold and tissue culture plate systems. Molecularly, increased chemoresistance is associated with the upregulation of discoidin domain receptor 1 (DDR1) and transcription factor STAT3. Inhibition of DDR1 activity by DDR1-specific inhibitor DDR-IN-1 accelerated cell death in the presence of Ara-C, DNR or their combination. These results demonstrated that $3 \mathrm{D}$ culture enhances chemoresistance of ALL Jurkat cell line by increasing DDR1 expression. Importantly, the cell adhesion-mediated drug resistance induced by DDR1 in the scaffold was similar to the clinical situation, indicating the 3D culture of cancer cells recapitulate the in vivo tumor environment and this platform can be used as a promising pre-clinic drug-screen system.
\end{abstract}

Correspondence to: Dr Chunting Zhao, Department of Hematology, Affiliated Hospital of Qingdao University, 16 Jiangsu Road, Qingdao, Shandong 266555, P.R. China

E-mail: tq462h@163.com; ctzhao-006@medmail.com.cn

*Contributed equally

Key words: 3D culture, daunorubicin, cytarabine, discoidin domain receptor 1 , resistance

\section{Introduction}

Hematological malignancy of acute leukemia is highly heterogeneous. At present, there are no standardized chemotherapy regimens for acute lymphoblastic leukemia (ALL) bone marrow microenvironment (1), with specific three dimensional (3D) structure, can support the growth of leukemia cells as well as protect them from chemotherapy drug induced death (2-4). 3D scaffold needs some properties to better mimic the bone marrow environment, such as adequate pore size, interconnected pores and high surface area, which will facilitate cells penetration and the formation of cellular associations (5). 3D scaffold provides greater physiological relevance in comparison with conventional 2D culture (6). The shortcoming of $2 \mathrm{D}$ culture is getting increasingly obvious by studies showing that cell behavior and gene expression are significantly influenced by the physical and mechanical properties of their microenvironment (7). Of the drug discoveries based on 2D culture $95 \%$ fail to provide clinical benefit (8). In this study, we compared the effects of $3 \mathrm{D}$ and $2 \mathrm{D}$ culture on drug resistance of leukemic cells. Polycaprolactone (PCL) is widely used as a 3D scaffold material for its good biocompatibility and biodegradability $(9,10)$. For cell culture experiments, the scaffold with a fiber size of $300 \mathrm{~nm}$ in diameter and a pore size of $300 \mathrm{~nm}$ diameter was used. PCL scaffold increased cell survival and drug resistance toward chemotherapy drug Ara-C and daunorubicin (DNR). Importantly, we found that the molecular mechanisms of cell survival and drug resistance observed in the scaffold were similar to those reported in vivo. Moreover, we explored how to reverse the drug resistance in 3D culture. The developed, molecularly characterized PCL scaffold could serve as a drug-testing platform for chemotherapies against drug-resistant cells.

\section{Materials and methods}

Materials. Cell counting kit-8 (CCK-8) and polyvinylidene fluoride (PVDF) membrane were purchased from Beyotime Biotechnology (Shanghai, China). BCA protein assay kit, protease inhibitor cocktail and RIPA lysis buffer were 
purchased from CWBiotech Co. Ltd. (Beijing, China). Rat-tail type I collagen were purchased from Solarbio Science \& Technology Co., Ltd. (Beijing, China). Ara-C, DNR and discoidin domain receptor 1 (DDR1)-IN-1 were purchased from MedChemExpress USA (New Jersey, USA), RPMI-1640 media was purchased from Hyclone (GE Healthcare Life Sciences, Logan, UT, USA). Fetal bovine serum (FBS) was purchased from Biological Industries (Beit Haemek, Israel). CD2-PC5 (cat. no. A07745), CD3-ECD (cat. no. A07748), CD4-FITC (cat. no. A07751), CD8-PE (cat. no. A07756), CD34-ECD (cat. no. B49202), (cat. no. B36294), all purchased from Beckman coulter, Inc. (Brea, CA, USA). Stat3 (cat. no. 9139), DDR1 (no. 5583), p-STAT3 (no. 9145), GAPDH (cat. no. 5174s), primary antibodies, goat anti-mouse (cat. no. 7076s) and rabbit HRP-conjugated secondary antibody (cat. no. 14708s) were purchased from Cell Signaling Technology, Inc., (Danvers, MA, USA). PCL scaffolds were purchased from 3D Biotek LLC (New Jersey, USA).

The study was approved by the Ethics Committee of Qingdao University (Qingdao, China).

Scaffold coating. Collagen, a major extracellular matrix (ECM) component, is coated to scaffold to make cell adhere better and as a ligand of DDR1 (11). DDR1 functions as the unique receptor tyrosine kinase (RTK) which can be activated by collagen $(12,13)$. PCL scaffolds were transferred into the 24-well plates and coated with collagen type I in different concentrations $(10,20,40,80,160$ and $320 \mu \mathrm{g} / \mathrm{ml})$. Then the PCL scaffold was dried in biosafety hood overnight.

Cell culture. The acute T leukemia cell line Jurkat, Clone E6-1 (ATCC ${ }^{\circledR}$ TIB-152 ${ }^{\mathrm{TM}}$ ) was cultured in RPMI-1640 supplemented with $10 \%$ FBS and $1 \%$ penicillin/streptomycin. The cells were maintained at $37^{\circ} \mathrm{C}$ with $5 \% \mathrm{CO}_{2}$ and $95 \%$ air (13). For experiments on scaffolds, the seeding density is different from $2.5 \times 10^{5}$ to $5 \times 10^{5}$ cells $/ \mathrm{ml}$ according to experiments and the seeding method was in strict accordance to the $3 \mathrm{D}$ Insert $^{\mathrm{TM}}$ cell seeding protocol.

Cell proliferation and viability. Cell seeding efficiency was determined $4 \mathrm{~h}$ after seeding into scaffold by counting the number of cells remaining in the media (14). Cell proliferation/viability was assessed for 6, 24, 48, 96, 144 and $168 \mathrm{~h}$ using CCK-8 reagent. Jurkat cells were seeded at a density of $2.5 \times 10^{5}$ cells $/ \mathrm{ml}$ and incubated with CCK-8 reagent for $2 \mathrm{~h}$ at $37^{\circ} \mathrm{C}$. A total of $100 \mu \mathrm{l}$ solution was taken for recording the optical density after incubation. Absorbance at $450 \mathrm{~nm}$ was measured using the Tecan Safire 2 multifunctional microplate reader.

Scanning electron microscopy (SEM). In order to visualize the growth of the cells in the scaffold, the scaffold was examined by SEM (JSM-840; JEOL, Ltd., Tokyo, Japan) following cultivation with the Jurkat cells for 72 and 144 h. Briefly, the scaffold was treated with $3 \%$ glutaral for $4 \mathrm{~h}$. Then, the scaffold was washed twice with PBS, following 30, 50, 70, 80 and $100 \%$ ethanol for dehydration. Then the carbon dioxide critical point dryer (XD-1; Eiko, Japan) was used to dry the scaffold. Prior to SEM analysis, samples were coated with gold for $120 \mathrm{sec}$ using auto fine coater (IB-3; EiKo, Japan).
Flow cytometry analysis. Flow cytometry analysis was performed to analyze whether the cell phenotype changes after cultivation in scaffold for one week. The expression of CD2, CD3, CD4, CD8, CD34 and CD45 were analyzed. Briefly, nonadherent cells were removed by PBS washing, then the cells were digested from the scaffold by collagenase treatment. After digestion, cells were harvested by gently pipetting the cell suspension up and down five times within the scaffold. Then the supernatant was centrifuged at $100 \mathrm{x} \mathrm{g}$ for $5 \mathrm{~min}$ to pellet the cells. The cells pellet was resuspended in PBS and incubated with antibodies for $15 \mathrm{~min}$ at $37^{\circ} \mathrm{C}$. Flow cytometry analysis was performed using FC500 (Beckman Coulter, Inc., Brea, CA, USA). Isotypes were used as a control.

Western blot analysis. The cells were lysed with RIPA buffer containing phosphatase and protease inhibitor cocktail. Protein was extracted from cells using an ultrasonicator for two cycles, $5 \mathrm{sec}$ each time with a 10 -second interval. After incubation for $15 \mathrm{~min}$ on ice, the lysate was centrifuged at $15,493 \mathrm{x} \mathrm{g}$ for $20 \mathrm{~min}$. After centrifugation, the supernatant was collected and quantified with BCA protein assay. Total protein $(20 \mu \mathrm{g})$ was separated by $10 \%$ sodium dodecyl sulfate-polyacrylamide gel electrophoresis (SDS-PAGE) and transferred to PVDF membrane. After blocking with 5\% non-fat milk for $1 \mathrm{~h}$ at room temperature, the membranes were probed with primary antibody against DDR1, STAT3, p-STAT3 and GAPDH overnight at $4^{\circ} \mathrm{C}$, followed by incubation with HRP-conjugated secondary antibody. The immunoreactive bands were visualized using Fusion FX7 detection reagents (Vilber Lourmat, Marne-la-Vallée, France). Autoradiograms were scanned and the labeled bands were quantified using Image $\mathbf{J}$ analysis software (National Institutes of Health, Bethesda, MD, USA).

Chemoresistance of cells cultured on scaffolds. 3D culture platforms are capable of mimicking microenvironments in vivo, which provide greater physiological relevance in comparison to conventional 2D cultures (15-18). Ara-C $(1 \mu \mathrm{M})$ and DNR (500 nM) were used in our experiments according to the clinical application $5 \times 10^{5} / \mathrm{ml}$ Jurkat cells were seeded into the tissue culture plate systems (TCPS), uncoated PCL scaffold (UPS) and collagen type I coated polycaprolactone scaffold (CTCPS) for $24 \mathrm{~h}$. Nonadherent cells were removed along with the medium and new medium with or without drugs was added. For TCPS, cells were taken out with medium and centrifuged. After removing the medium, the cells were seeded into wells and medium with or without drugs was added. The medium was replaced every $48 \mathrm{~h}$. Das et al found that inhibition of DDR1 expression significantly enhanced chemosensitivity of breast cancer cells to genotoxic drugs (19). Thus, DDR1 signaling provides a new target for therapeutic intervention to leukemia cells. DDR1IN-1, an orally bioavailable DDR1 inhibitor $(20,21)$, was used in our experiments.

Statistical analysis. All experimental data were analyzed by Student's t-test. All experiments were done three times. Data are presented as mean \pm standard error. $\mathrm{P}<0.05$ was considered to indicate a statistically significant difference. All tests were completed using PRISM 6 (GraphPad Software, Inc., La Jolla, CA, USA). 

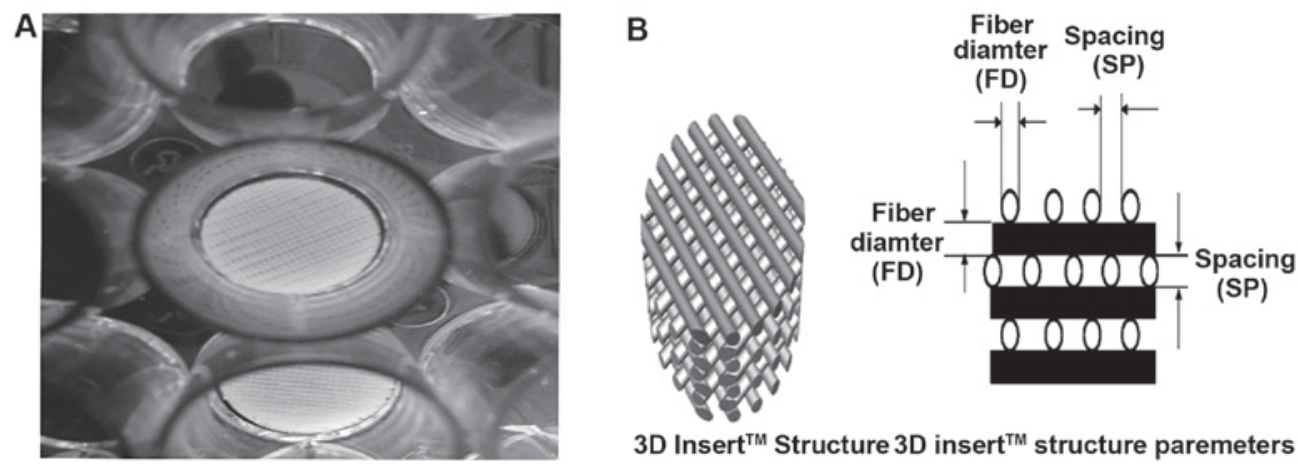

3D Insert ${ }^{\mathrm{TM}}$ Structure 3D insert ${ }^{\mathrm{TM}}$ structure paremeters

Figure 1. The morphological and structure characteristics of PCL scaffold and the morphology of Jurkat cells. (A) The morphological characteristics of the PCL scaffold in 24 wells. (B) The structure parameters of PCL scaffold: Fiber size of $300 \mathrm{~nm}$ in diameter and a pore size of $300 \mathrm{~nm}$ diameter. PCL, polycaprolactone.

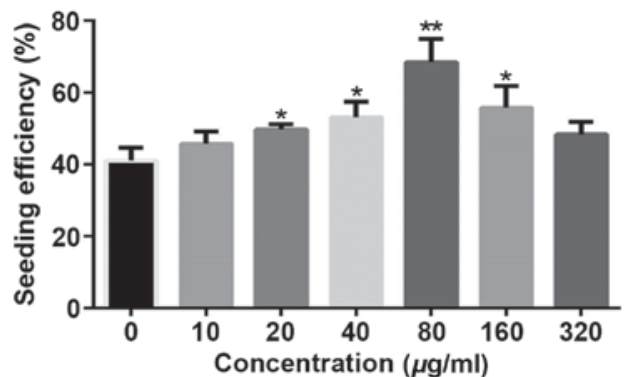

Figure 2. The effect of different concentrations of collagen type I on the seeding efficiency. Seeding efficiency was detected at $12 \mathrm{~h}$ after incubation the Jurkat cell into the scaffold. A total of $20,40,80,160 \mu \mathrm{g} / \mathrm{ml}$ CTCPS displayed a $>50 \%$ seeding efficiency with a statistically significant higher seeding efficiency than the rest $\left({ }^{*} \mathrm{P}<0.05,{ }^{* *} \mathrm{P}<0.01\right)$. CTCPS, collagen type I coated polycaprolactone scaffold.

\section{Results}

PCL scaffold coating with ECM proteins. Collagen type I is one of the main bone marrow ECM proteins and also the ligand of DDR1 (22). In order to mimic the bone marrow microenvironment and further study the function of DDR1, PCL scaffold coating with collagen type I was used in our experiments (Fig. 1). The effect of different concentrations of collagen type I on the cell seeding and cell proliferation was improved compared to UPS. Indeed, collagen type I coating enhanced the seeding efficiency. The seeding efficiency increased gradually at low concentration of collagen type I, but decreased at high concentration (160 or $320 \mu \mathrm{g} / \mathrm{ml})$ when compared with $80 \mu \mathrm{g} / \mathrm{ml}$ collagen type I coated PCL scaffolds (Fig. 2).

Cell proliferation on different scaffolds. To investigate the effect of PCL scaffold on cell proliferation, we compared proliferation of Jurkat cells on TCPS, UPS and $80 \mu \mathrm{g} / \mathrm{ml}$ CTCPS for $168 \mathrm{~h}$. CCK- 8 reagent was used to analyze the extent of cell proliferation/viability. Different growth kinetics were observed for Jurkat cells cultured on different conditions. Coating the PCL scaffold with collagen type I enhanced cell proliferation compared with the TCPS and UPS, especially for a longer time culture. For the initial 96 h, the TCPS revealed the maximum cell proliferation/viability compared with the UPS and CTCPS. However, with the prolongation of the cell

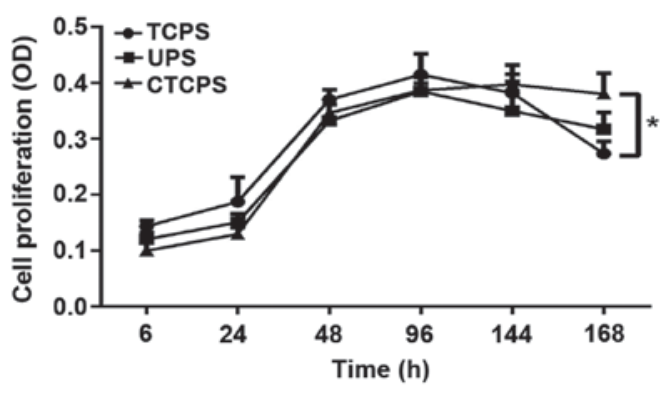

Figure 3. Comparison of proliferation of Jurkat cells on TCPS, UPS and $80 \mu \mathrm{g} / \mathrm{ml}$ CTCPS at different time-points. The increased cell proliferation observed in $80 \mu \mathrm{g} / \mathrm{ml} \mathrm{CTCPS}$ at 144 and $168 \mathrm{~h}$. ${ }^{*} \mathrm{P}<0.05$ for CTCPS vs. TCPS at $168 \mathrm{~h}$. TCPS, tissue culture plate systems; UPS, uncoated PCL scaffold; CTCPS, collagen type I coated polycaprolactone scaffold.

culturing, the CTCPS showed better cell proliferation than the UPS. Moreover, CTCPS can maintain cell proliferation for $168 \mathrm{~h}$. After $166 \mathrm{~h}$, the TCPS revealed a significant deterioration in cell proliferation (Fig. 3).

Cellular phenotype analysis. The cell proliferation/viability result showed that $80 \mu \mathrm{g} / \mathrm{ml}$ CTCPS was able to support cell survival and proliferation better. It is very important for cells to maintain the initial phenotype and not differentiate with the prolongation of the cell culture. The expression of CD2, CD3, CD4, CD8, CD34, CD45 in Jurkat cells cultured in different conditions such as UPS and $80 \mu \mathrm{g} / \mathrm{ml} \mathrm{CTCPS}$ were analyzed at $168 \mathrm{~h}$. The results showed that the percentage of cells with the phenotype of $\mathrm{CD} 2{ }^{+} \mathrm{CD}^{+} \mathrm{CD} 4{ }^{+\mathrm{dim}} \mathrm{CD} 8{ }^{-} \mathrm{CD} 34{ }^{-} \mathrm{CD} 45^{+\mathrm{dim}}$ was maintained for $168 \mathrm{~h}$ of culture on the scaffolds compared to that cultured on TCPS (Fig. 4). Similarly, the phenotype of Jurkat cell on the CTCPS and UPS showed no difference in comparison to the TCPS for $168 \mathrm{~h}$.

Sensitivity of drugs on Jurkat cells at TCPS, UPS and CTCPS. The $80 \mu \mathrm{g} / \mathrm{ml}$ CTCPS was more suitable for cell proliferation and growth for a longer period without changing cell phenotype. So we used $80 \mu \mathrm{g} / \mathrm{ml} \mathrm{CTCPS} \mathrm{for} \mathrm{drug} \mathrm{testing}$ applications. Jurkat cells were treated with Ara-C and DNR or their combination (Fig. 5). CCK-8 reagent was used to test cell cytotoxicity of Jurkat cells cultured on TCPS, UPS and $80 \mu \mathrm{g} / \mathrm{ml}$ CTCPS. Jurkat cells revealed high sensitivity 

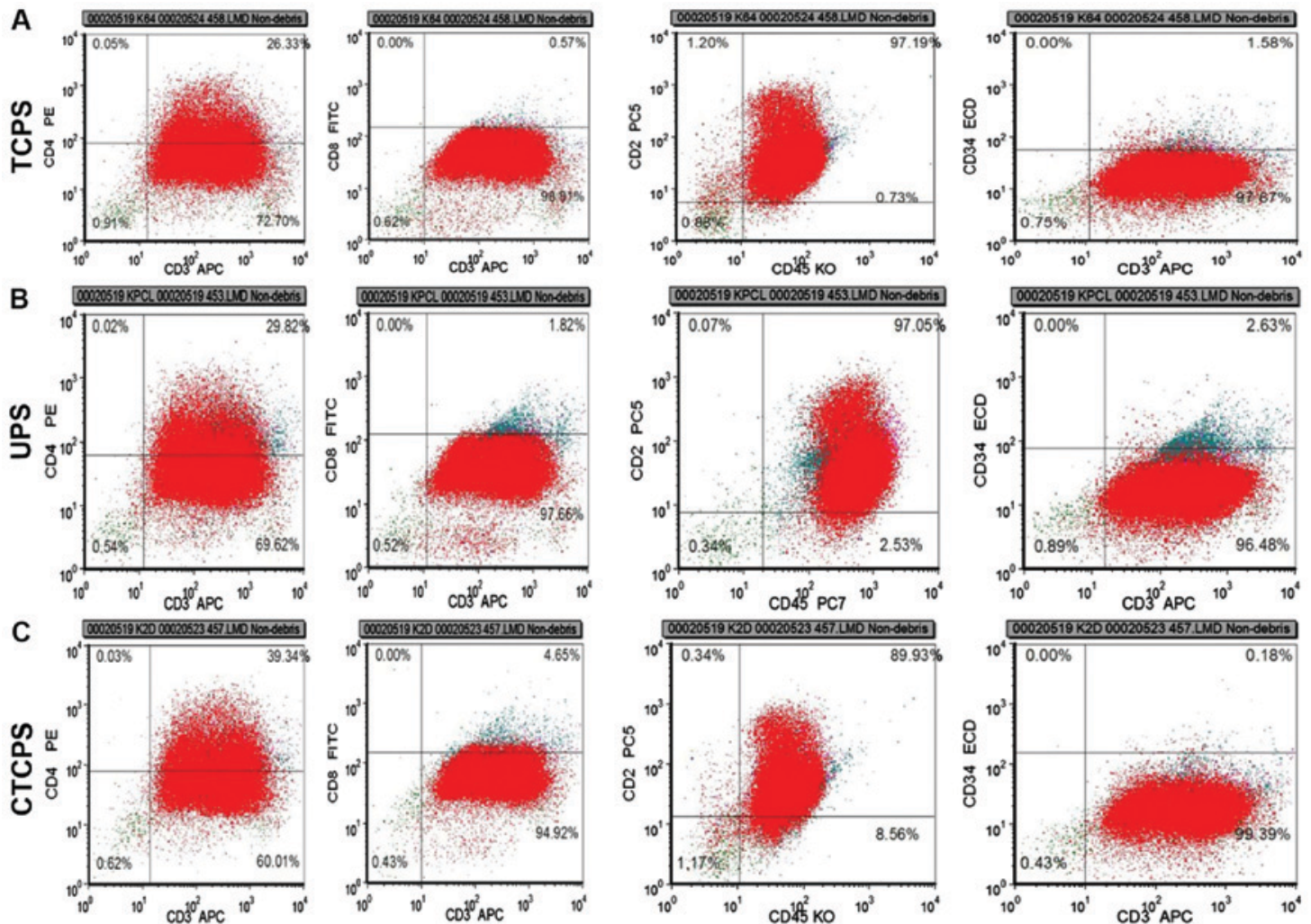

Figure 4. Jurkat phenotype maintenance on PCL scaffolds. Fluorescence-activated cell sorting analysis of Jurkat cells phenotype after seeding at different conditions (UPS and $80 \mu \mathrm{g} / \mathrm{ml}$ CTCPS) at $168 \mathrm{~h}$. (A) The initial phenotype of Jurkat cell at TCPS. The phenotype of Jurkat cells at $168 \mathrm{~h}$ after incubation with (B) UPS and (C) $80 \mu \mathrm{g} / \mathrm{ml}$ CTCPS. Note the percentage of expression of CD2, CD3, CD4, CD8, CD34, CD45. PCL, polycaprolactone; TCPS, tissue culture plate systems; UPS, uncoated PCL scaffold; CTCPS, collagen type I coated PCL scaffold.
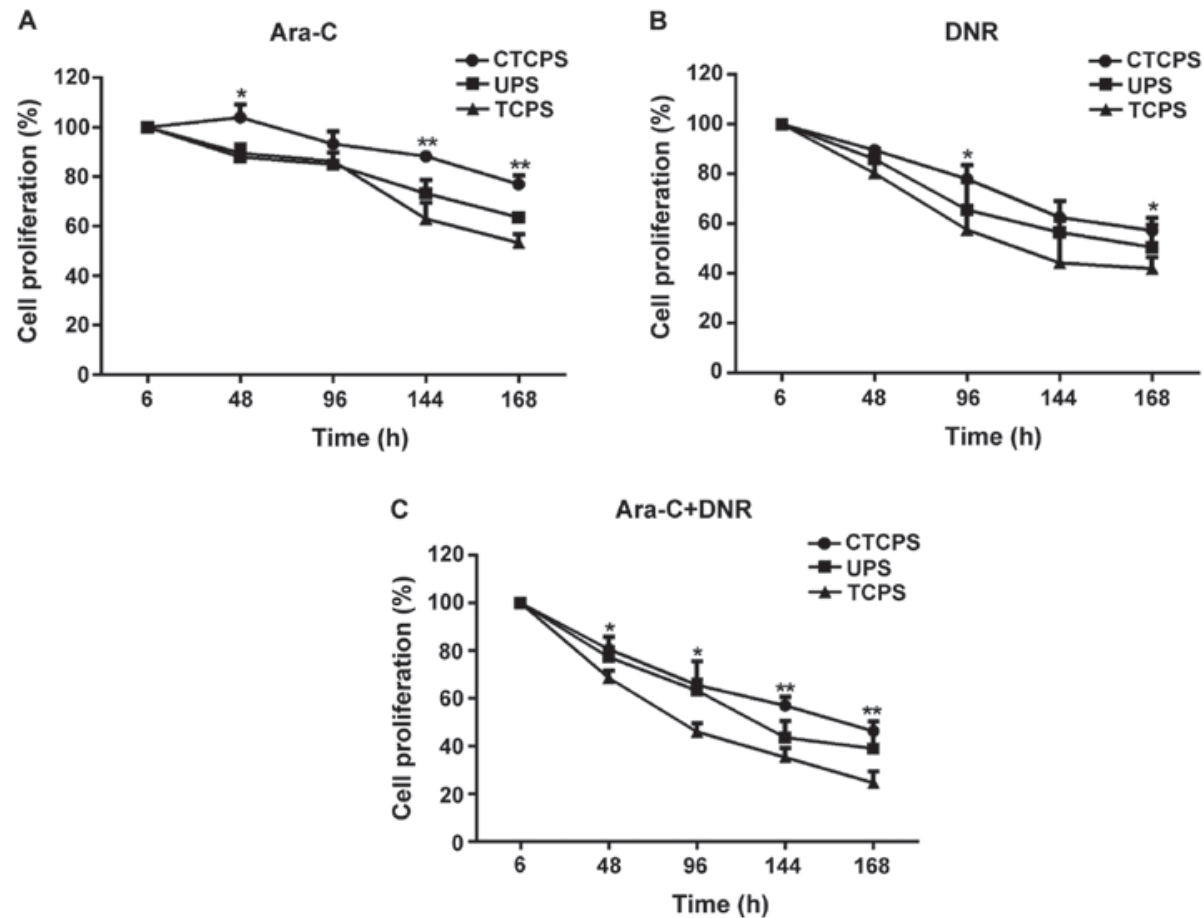

Figure 5. Comparison of sensitivity of Jurkat cell to (A) Ara-C, (B) DNR, and (C) combination of both on a TCPS, UPS, and $80 \mu \mathrm{g} / \mathrm{ml}$ (CTCPS). A total of $80 \mu \mathrm{g} / \mathrm{ml}$ CTCPS was different from TCPS and ${ }^{*} \mathrm{P}<0.05,{ }^{* *} \mathrm{P}<0.01 \mathrm{vs}$. TCPS at different time-points in Ara-C, DNR, and combination of both. Ara-C, cytarabine; DNR, daunorubicin; TCPS, tissue culture plate system; UPS, uncoated PCL scaffold; CTCPS, collagen type I coated PCL scaffold.

to Ara-C cultured on TCPS. Cell proliferation reduced to $89.58 \pm 3.26,62.86 \pm 6.84$ and $53.36 \pm 3.37 \%$ for 48,144 and $168 \mathrm{~h}$ respectively on TCPS, according to the CCK- 8 results (Fig. 5A). Cells cultured on $80 \mu \mathrm{g} / \mathrm{ml}$ CTCPS showed 
A

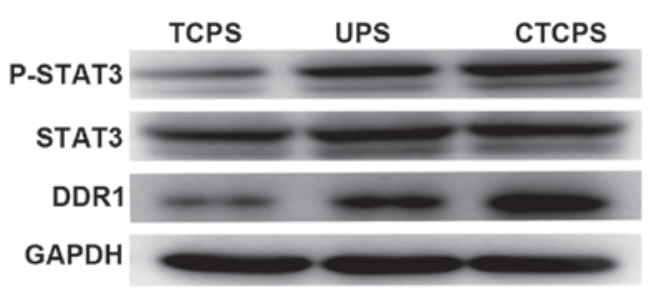

B
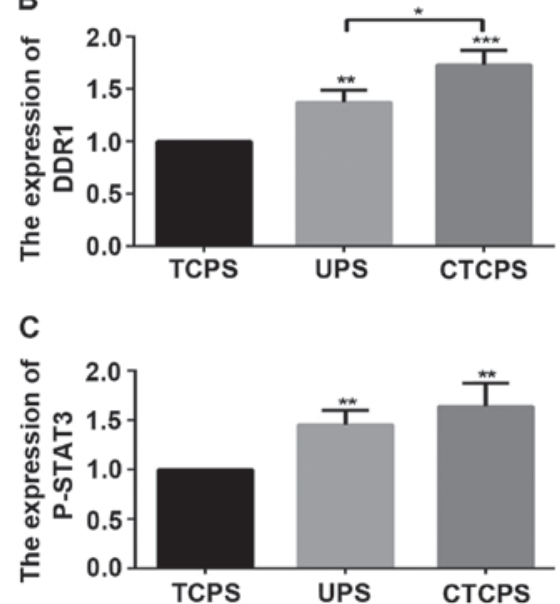

D

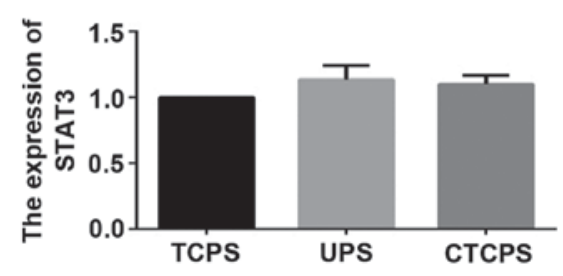

Figure 6. Comparison of the expression of DDR1, STAT3 and P-STAT3 in Jurkat cells on a TCPS, UPS and $80 \mu \mathrm{g} / \mathrm{ml}$ CTCPS for $96 \mathrm{~h}$. (A) The expression levels of DDR1, STAT3 and P-STAT3 in Jurkat cell in different conditions. The expression of P-STAT3 and DDR1 are both increased in UPS and CTCPS. (B) Quantified results of expression levels of DDR1. (C) Quantified results of expression levels of P-STAT3. (D) Quantified results of expression levels of STAT3. ${ }^{*} \mathrm{P}<0.05,{ }^{* *} \mathrm{P}<0.01,{ }^{* * * *} \mathrm{P}<0.001$. DDR1, discoidin domain receptor 1 ; TCPS, tissue culture plate system; UPS, uncoated polycaprolactone scaffold; CTCPS, collagen type I coated PCL scaffold.

resistance to drug treatment, as shown by the result that cell proliferation was $103.98 \pm 5.3,88.69 \pm 2.19,77.11 \pm 3.47 \%$ at 48 , 144 and $168 \mathrm{~h}$. Moreover, the drug sensitivity of cells cultured on UPS was between TCPS and CTCPS, with the relative percentage of $87.98 \pm 3.74,73.28 \pm 5.5$ and $63.65 \pm 0.81 \%$ at 48, 144 and $168 \mathrm{~h}$. Cells cultured under the three conditions showed more sensitivity to DNR or Ara-C + DNR combination than Ara-C alone. A significant death of Jurkat cells was observed in TCPS $(57.67 \pm 8.02,42 \pm 4.58 \%)$ when compared to CTCPS $(78 \pm 5.57,57.33 \pm 5.03 \%)$ in the presence of DNR for 96 and $168 \mathrm{~h}$ (Fig. 5B; ${ }^{*} \mathrm{P}<0.05$ vs. TCPS). A similar trend of combination use of Ara-C and DNR was obtained in TCPS $(24.67 \pm 4.73 \%)$ and UPS cultures $(39 \pm 7.55 \%)$ in comparison to $80 \mu \mathrm{g} / \mathrm{ml}$ CTCPS $(46.33 \pm 4.04 \%)$ for $168 \mathrm{~h}$ (Fig. $5 \mathrm{C}$; ${ }^{* *} \mathrm{P}<0.01$ vs. TCPS). In general, the cells cultured on $80 \mu \mathrm{g} / \mathrm{ml}$ CTCPS showed drug resistance for a longer culture period compared with TCPS and UPS.

DDR1 and p-STAT3 mediated cell chemoresistance in CTCPS. We have shown that cell cultured on $80 \mu \mathrm{g} / \mathrm{ml}$ CTCPS revealed chemoresistance compared to TCPS. We further explored the possible mechanisms that lead to cell chemoresistance. Evidence suggests that high expression of DDR1 and p-STAT3 is related to cell proliferation, invasion, migration and chemoresistance of malignant tumors $(23,24)$. STAT3 is the downstream effector of DDR1 pathway and STAT3 can be phosphorylated by DDR1 $(25,26)$. Therefore, we wanted to verify whether the drug resistance to Ara-C and DNR of cells cultured in 3D scaffold is related to the high expression of DDR1 and p-STAT3. The levels of DDR1 and p-STAT3 were highly expressed on the UPS and $80 \mu \mathrm{g} / \mathrm{ml}$ CTCPS compared to the TCPS (Fig. 6). Next, we chose DDR1-IN-1, a potent and selective DDR1 receptor tyrosine kinase inhibitor (21), to further analyze whether DDR1 inhibition would reverse the chemoresistance. The concentration of DDR1-IN-1 used was determined in Jurkat cells cultured in TCPS (Fig. 7A). $\mathrm{IC}_{50}$ of $335 \mathrm{nM}$ with DNR was chosen for further experiments. DDR1-IN-1 (1 $\mu \mathrm{M})$ which is sufficient to inhibit DDR1 autophosphorylation alone did not inhibit cell proliferation after incubation for $48 \mathrm{~h}$, whereas Ara-C (Fig. 7B) and DNR (Fig. 7C) singly or in combination (Fig. 7D), along with DDR1-IN-1 induced significant cell death, wherein almost all the cells were wiped out in contrast with DDR1-IN-1 alone at $144 \mathrm{~h}$.

\section{Discussion}

ALL is still a disease that cannot be completely cured by chemotherapy. Hematopoietic stem cell transplantation is the only way to cure leukemia. However, the high cost, easy relapse, severe GVHD side effects and technical limitations make hematopoietic stem cell transplantation hard to carry out for most leukemia patients in China (27). In recent years, the research and development of targeted drugs has become a hot spot $(28,29)$. The prognosis of many hematological malignancies has greatly improved because of the new drugs (30). Drug testing in vitro needs an environment similar to the niche in vivo where those cells reside (31). Although researchers are trying to establish cell microenvironments in vitro which is closer to the bone marrow niche in vivo, the 

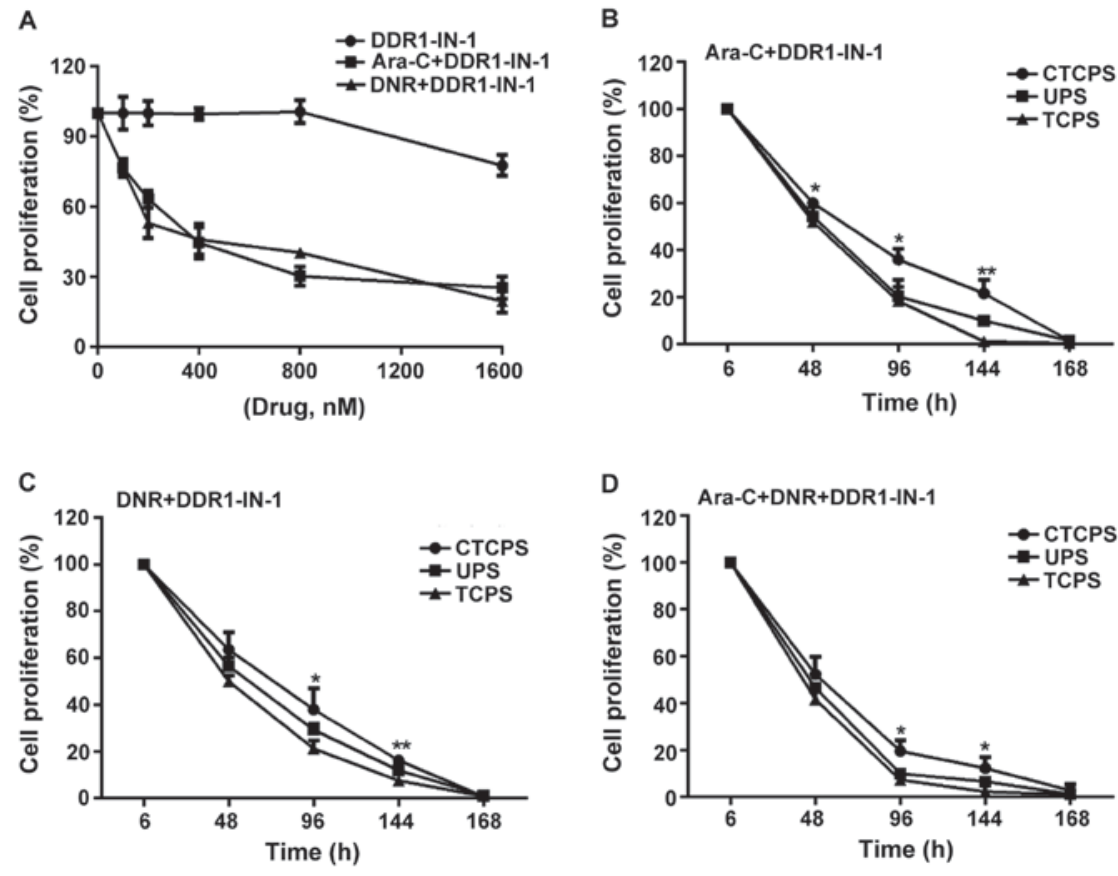

Figure 7. Effect of the DDR1 inhibitor DDR1-1N-1 in inducing cell death in the presence of Ara-C and DNR. Different concentration of DDR1-IN-1 combine with Ara-C or DNR in inducing cell death at $48 \mathrm{~h}$. $\mathrm{IC}_{50}=354.4 \mathrm{nM}$ with Ara-C, $\mathrm{IC}_{50}=335 \mathrm{nM}$ with DNR. (A) The increased cell death induced by both Ara-C and DNR on the $80 \mu \mathrm{g} / \mathrm{ml}$ CTCPS at 96, 144 and $168 \mathrm{~h}$. (B-D) Following treatment with DDR1-IN-1. ${ }^{*} \mathrm{P}<0.05,{ }^{* *} \mathrm{P}<0.01$ vs. TCPS at different time-points. DDR1, discoidin domain receptor 1; Ara-C, cytarabine; DNR, daunorubicin; TCPS, tissue culture plate system; CTCPS, collagen type I coated PCL scaffold.
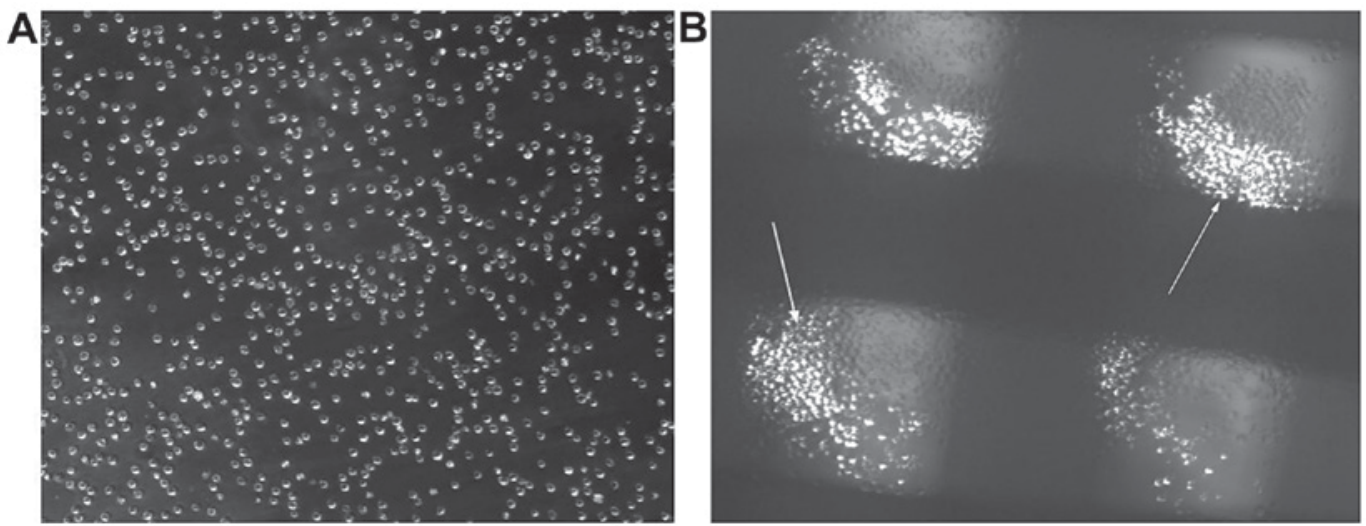

Figure 8. The morphology of Jurkat cells. (A) Morphology of Jurkat cells cultured in the TCPS. (B) Morphology of Jurkat cells adhered to the PCL scaffold and aggregation growth. TCPS, tissue culture plate systems; PCL, polycaprolactone.
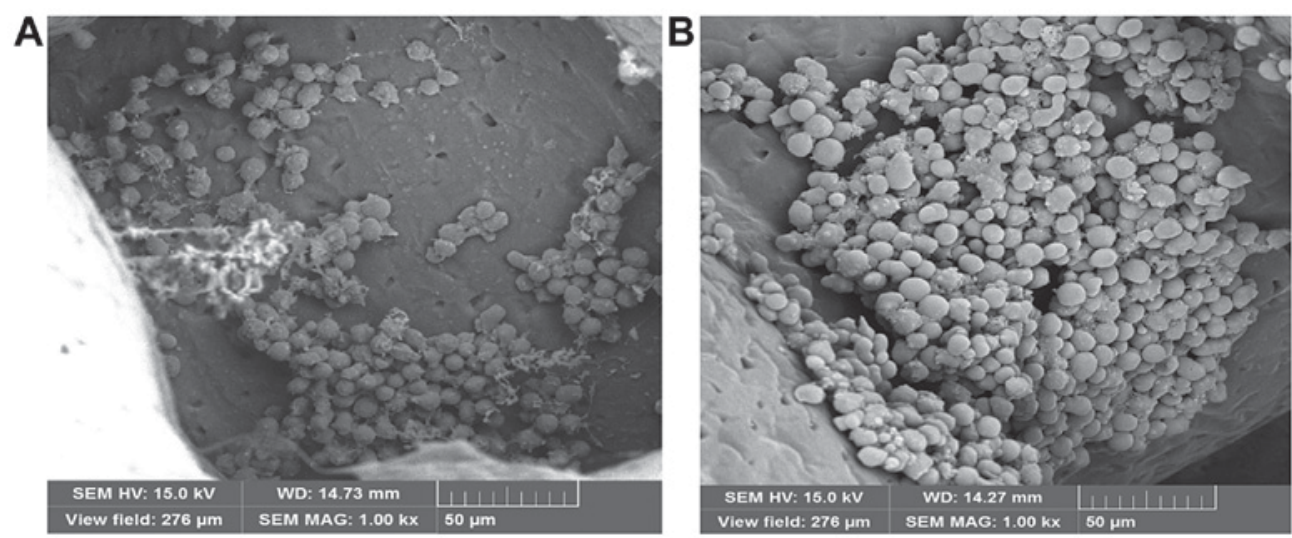

Figure 9. Scanning electron micrographs of PCL scaffolds coated with collagen type I. (A) The $80 \mu \mathrm{g} / \mathrm{ml}$ cultured with the Jurkat cells at $72 \mathrm{~h}$. Jurkat cells adhere to the surface of the scaffold and grow in a cluster. (B) The PCL scaffold coated with $80 \mu \mathrm{g} / \mathrm{ml}$ collagen type I cultured with the Jurkat cells at $144 \mathrm{~h}$. Large numbers of cells divide and aggregate into globes. PCL, polycaprolactone. 
progress is unsatisfactory. Since leukemia cells reside in the bone marrow niche, where leukemia cells escape from the chemotherapy drugs $(32,33)$. Compared with traditional 2D culture, 3D Insert ${ }^{\mathrm{TM}}$ PCL scaffold is a lot more like in vivo environment. Cells expanded on the scaffolds have more physiological-like morphology and function (Figs. 8 and 9). In order to mimic bone marrow microenvironment, the scaffolds are coated with collagen. The results showed that the concentration of $80 \mu \mathrm{g} / \mathrm{ml} \mathrm{CTCPS}$ is the maximum cell seeding efficiency, whereas the high concentration $(160,320 \mu \mathrm{g} / \mathrm{ml})$ leads to a decrease of seeding efficiency. This may be attributed to the quick gel formation rate of high concentration of collagen type I, which blocks the infiltration and migration of Jurkat cells.

The initial cell proliferation lag on scaffolds compared to that in TCPS could be attributed to the limited cells bound to the surface and the scaffold niche at the time of seeding (in order to reduce the number of cell culture medium replaced, we seeded $2 \times 10^{4}$ cells per well on scaffold), the cells also need an adaptive process for new culture environments. That is the possible reason why the proliferation of cells for 48 and $96 \mathrm{~h}$ on TCPS was higher than that on UPS and CTCPS. With the prolongation of culture time, more cells adhere to the scaffold surface, divide and migrate into the scaffold and get adapted to the new culture environments. Moreover, this scenario was lacking in the TCPS; that is the possible reason why the cell proliferation was significantly reduced by 144 and $168 \mathrm{~h}$. With the increasing number of cells, the decrease of cell surface area for collagen type I adsorption is inevitable, leading to less area for cell attachment. Thereby G0/G1 cells decrease and non-adhered cells actively divide, overpopulate and die, indicating that CTCPS are more suitable than TCPS and UPS for longer time culture $(14,34)$.

We further explored whether different culture conditions lead to changes in cell phenotype. The result showed that despite culturing Jurkat cells for $168 \mathrm{~h}$, the original phenotype of Jurkat cells was retained the same on the $80 \mu \mathrm{g} / \mathrm{ml}$ CTCPS and UPS compared to TCPS. That is an important characteristic in studies of leukemia cells. It has been reported that DDR1 activates STAT3 signaling during tumor progression in human breast cancer metastasis (25). Overexpression of discoidin DDR1 enhanced the cisplatin resistance of ovarian cancer cells (35), but in ALL, the expression and effect of DDR1 on the drug-resistance is not yet clear. The result showed that the expression levels of DDR1, P-STAT3 in Jurkat cells cultured in the CTCPS were higher than those of cells cultured in TCPS significantly suggesting that the increased expression of DDR1 activated by collagen type I may be the possible reason for the cell survival. The cells grow in a 3D environment may contribute to the expression of DDR1, and may be the reason why the expression levels of DDR 1 in the UPS were higher than in the TCPS. The treatment of Jurkat cells cultured on CTCPS with Ara-C, DNR or their combination revealed low sensitivity compared with TCPS until the $168 \mathrm{~h}$. The conclusion of the experiment proves that DDR1/ STAT3 mediated mechanism may be the reason of Jurkat cell chemoresistance. We hypothesize that the collagen type I promote the Jurkat cells to harbor in the 3-D niche of the scaffold and activate the DDR1 protein as a ligand. Activation of the DDR1 pathway leads to cell chemoresistance (19).
To further confirm the mechanism, we use DDR1 receptor tyrosine kinase inhibitor DDR1-IN-1 to block DDR1. By blocking the function of DDR1, the sensitivity of leukemic cells to chemotherapeutic drugs is enhanced. These results indicate that the explored CTCPS could support chemotherapy drug resistance to Ara-C, DNR or combination and chemoresistance mechanism operates through the DDR1/STAT3 pathway, recapitulating at least in part the drug resistance seen in the in vivo condition. Thus 3D architecture is also important in providing the chemoresistance. This could be attributed to the similar morphology of the PCL scaffolds to the bone marrow, as collagen type I helps in cell chemoresistance by activating DDR1 (36).

Biomimetic structure is an important parameter in the clinical trial of drugs. Because in some cases the cells were sensitive to the drug in $2 \mathrm{D}$ culture, but were resistant to $3 \mathrm{D}$ culture $(37,38)$. On one hand, we think that the bionic 3D scaffold with the capability of supporting the leukemic cells for a longer period has immense potential in drug screening. On the other hand, in response to DDR1 as a drug target, drugs can be designed for the treatment of leukemia, which include antibodies against the DDR1 ligand or the receptor itself or a small molecular chemical inhibitor for the intracellular domain of DDR1 kinase. The application of 3D cell culture system enables researchers to create superior in vitro models to obtain more realistic physiological results from studies in vitro. As a result, the use of $3 \mathrm{D}$ cell culture will decrease the overall therapeutic and pharmaceutical product development cost and shorten the time to market.

\section{Acknowledgements}

Not applicable.

\section{Funding}

The project described was supported by Qingdao City People's Livelihood Science and technology project (16-62-30-nsh).

\section{Availability of data and materials}

The datasets used and/or analyzed during the present study are available from the corresponding author on reasonable request.

\section{Authors' contributions}

JG and $\mathrm{CZ}$ conceived and designed the study and were responsible for cell culture. RY, AS, LS, XL, SW, ZS and TL detected cell proliferation and viability and performed flow cytometry analysis. SL, YG, JL, XF and WW contributed to western blot analysis. HZ, ZC, GL and FM analyzed chemoresistance of cells cultured on scaffolds. All authors read and approved the final manuscript.

\section{Ethics approval and consent to participate}

The study was approved by the Ethics Committee of Qingdao University (Qingdao, China). 


\section{Patient consent for publication}

Not applicable.

\section{Competing interests}

The authors declare that they have no competing interests.

\section{References}

1. Nair MS, Mony U, Menon D, Koyakutty M, Sidharthan N, Pavithran K, Nair SV and Menon KN: Development and molecular characterization of polymeric micro-nanofibrous scaffold of a defined 3-D niche for in vitro chemosensitivity analysis against acute myeloid leukemia cells. Int J Nanomedicine 10: 3603-3622, 2015.

2. Funayama K, Murai F, Shimane M, Nomura H and Asano S: Adhesion-induced drug resistance in leukemia stem cells. Pharmacology 86: 79-84, 2010 .

3. Wojtkowiak JW, Verduzco D, Schramm KJ and Gillies RJ: Drug resistance and cellular adaptation to tumor acidic $\mathrm{pH}$ microenvironment. Mol Pharm 8: 2032-2038, 2011.

4. Wang JY, Yu P, Chen S, Xing H, Chen Y, Wang M, Tang K, Tian Z, Rao Q and Wang J: Activation of Racl GTPase promotes leukemia cell chemotherapy resistance, quiescence and niche interaction. Mol Oncol 7: 907-916, 2013.

5. Dumbleton J, Agarwal P, Huang H, Hogrebe N, Han R, Gooch KJ and He X: The effect of RGD peptide on 2D and miniaturized 3D culture of HEPM cells, MSCs, and ADSCs with alginate hydrogel. Cell Mol Bioeng 9: 277-288, 2016.

6. Duval K, Grover H, Han LH, Mou Y, Pegoraro AF, Fredberg J and Chen Z: Modeling physiological events in $2 \mathrm{D}$ vs. $3 \mathrm{D}$ cel culture. Physiology (Bethesda) 32: 266-277, 2017.

7. Nugraha B, Mohr MA, Ponti A, Emmert MY, Weibel F, Hoerstrup SP, Moll S, Certa U, Prunotto M and Pantazis P: Monitoring and manipulating cellular crosstalk during kidney fibrosis inside a 3D in vitro co-culture. Sci Rep 7: 14490, 2017.

8. Hou J, Hong Z, Feng F, Chai Y, Zhang Y, Jiang Q, Hu Y, Wu S, Wu Y, Gao X, et al: A novel chemotherapeutic sensitivity-testing system based on collagen gel droplet embedded 3D-culture methods for hepatocellular carcinoma. BMC Cancer 17: 729, 2017.

9. Burton TP, Corcoran A and Callanan A: The effect of electrospun polycaprolactone scaffold morphology on human kidney epithelial cells. Biomed Mater 13: 015006, 2017.

10. Caicedo-Carvajal CE, Liu Q, Remache Y, Goy A and Suh KS Cancer tissue engineering: A novel 3D polystyrene scaffold for in vitro isolation and amplification of lymphoma cancer cells from heterogeneous cell mixtures. J Tissue Eng 2011: 362326, 2011.

11. Hur H, Ham IH, Lee D, Jin H, Aguilera KY, Oh HJ, Han SU, Kwon JE, Kim YB, Ding K, et al: Discoidin domain receptor 1 activity drives an aggressive phenotype in gastric carcinoma. BMC Cancer 17: 87, 2017.

12. Moreau V and Saltel F: Type I collagen fibrils and discoidin domain receptor 1 set invadosomes straight. Mol Cell Oncol 2: e1004963, 2015

13. Stępnik M, Spryszyńska S, Gorzkiewicz A and Ferlińska M Cytotoxicity of anticancer drugs and PJ-34 (poly(ADP-ribose) polymerase-1 (PARP-1) inhibitor) on HL-60 and Jurkat cells. Adv Clin Exp Med 26: 379-385, 2017.

14. Blanco TM, Mantalaris A, Bismarck A and Panoskaltsis N The development of a three-dimensional scaffold for ex vivo biomimicry of human acute myeloid leukaemia. Biomaterials 31 2243-2251, 2010

15. Bao M, Xie J, Piruska A and Huck WTS: 3D microniches reveal the importance of cell size and shape. Nat Commun 8: 1962, 2017.

16. BellCC,Dankers ACA,Lauschke VM, Sison-Young R, Jenkins R, Rowe C, Goldring CE, Park K, Regan SL, Walker T, et al: Comparison of hepatic 2D sandwich cultures and 3D spheroids for long-term toxicity applications: A multi-center study. Toxicol Sci 162: 655-666, 2018

17. Xue R, Qian Y, Li L, Yao G, Yang L and Sun Y: Polycaprolactone nanofiber scaffold enhances the osteogenic differentiation potency of various human tissue-derived mesenchymal stem cells. Stem Cell Res Ther 8: 148, 2017.
18. Yildirim ED, Besunder R, Pappas D, Allen F, Güçeri S and Sun W: Accelerated differentiation of osteoblast cells on polycaprolactone scaffolds driven by a combined effect of protein coating and plasma modification. Biofabrication 2: 014109, 2010

19. Das S, Ongusaha PP, Yang YS, Park JM, Aaronson SA and Lee SW: Discoidin domain receptor 1 receptor tyrosine kinase induces cyclooxygenase- 2 and promotes chemoresistance through nuclear factor-kappaB pathway activation. Cancer Res 66: 8123-8130, 2006

20. Canning P, Tan L, Chu K, Lee SW, Gray NS and Bullock AN Structural mechanisms determining inhibition of the collagen receptor DDR1 by selective and multi-targeted type II kinase inhibitors. J Mol Biol 426: 2457-2470, 2014.

21. Kim HG, Tan L, Weisberg EL, Liu F, Canning P, Choi HG, Ezell SA, Wu H, Zhao Z, Wang J, et al: Discovery of a potent and selective DDR1 receptor tyrosine kinase inhibitor. ACS Chem Biol 8: 2145-2150, 2013.

22. Fang Y, Wang B, Zhao Y, Xiao Z, Li J, Cui Y, Han S, Wei J, Chen B, Han J, et al: Collagen scaffold microenvironments modulate cell lineage commitment for differentiation of bone marrow cells into regulatory dendritic cells. Sci Rep 7: 42049, 2017.

23. Lin $\mathrm{CH}$, Chiang MC and Chen YJ: STAT3 mediates resistance to anoikis and promotes invasiveness of nasopharyngeal cancer cells. Int J Mol Med 40: 1549-1556, 2017.

24. Yang JC, Zhang Y, He SJ, Li MM, Cai XL, Wang H, Xu LM and Cao J: TM4SF1 promotes metastasis of pancreatic cancer via regulating the expression of DDR1. Sci Rep 7: 45895, 2017.

25. Gao H, Chakraborty G, Zhang Z, Akalay I, Gadiya M, Gao Y, Sinha S, Hu J, Jiang C, Akram M et al: Multi-organ site metastatic reactivation mediated by non-canonical discoidin domain receptor 1 signaling. Cell 166: 47-62, 2016.

26. Wang Z, Sun X, Bao Y, Mo J, Du H, Hu J and Zhang X: E2F1 silencing inhibits migration and invasion of osteosarcoma cells via regulating DDR1 expression. Int J Oncol 51: 1639-1650, 2017.

27. Yang $C$ and Zhang $X$ : Incidence survey of leukemia in China. Chin Med Sci J 6: 65-70, 1991.

28. Broxterman HJ and Georgopapadakou NH: Anticancer therapeutics: 'Addictive' targets, multi-targeted drugs, new drug combinations. Drug Resist Updat 8: 183-197, 2005.

29. Da Costa EM, McInnes G, Beaudry A and Raynal NJ: DNA methylation-targeted drugs. Cancer J 23: 270-276, 2017.

30. Jamison C, Nelson D, Eren M, Gauchan D, Ramaekers R, Norvell M and Copur MS: What is the optimal dose and schedule for dasatinib in chronic myeloid leukemia: Two case reports and review of the literature. Oncol Res 23: 1-5, 2015.

31. Wang JZ, Zhu YX, Ma HC, Chen SN, Chao JY, Ruan WD, Wang D, Du FG and Meng YZ: Developing multi-cellular tumor spheroid model (MCTS) in the chitosan/collagen/alginate (CCA) fibrous scaffold for anticancer drug screening. Mater Sci Eng C 62: 215-225, 2016.

32. Poulos MG, Gars EJ, Gutkin MC, Kloss CC, Ginsberg M, Scandura JM, Rafii S and Butler JM: Activation of the vascular niche supports leukemic progression and resistance to chemotherapy. Exp Hematol 42: 976-986.e3, 2014.

33. Prieto-Vila M, Takahashi RU, Usuba W, Kohama I and Ochiya T: Drug resistance driven by cancer stem cells and their niche. Int J Mol Sci 18: 2574, 2017.

34. Feng Q, Chai C, Jiang XS, Leong KW and Mao HQ: Expansion of engrafting human hematopoietic stem/progenitor cells in threedimensional scaffolds with surface-immobilized fibronectin. J Biomed Mater Res A 78: 781-791, 2006.

35. Deng Y, Zhao F, Hui L, Li X, Zhang D, Lin W, Chen Z and Ning Y: Suppressing miR-199a-3p by promoter methylation contributes to tumor aggressiveness and cisplatin resistance of ovarian cancer through promoting DDR1 expression. J Ovarian Res 10: 50, 2017.

36. Carbone A and Gloghini A: Activated DDR1 increases RS cell survival. Blood 122: 4152-4154, 2013

37. Kim MK, Kim Y, Choo H and Chong Y: Quercetin-glutamic acid conjugate with a non-hydrolysable linker; a novel scaffold for multidrug resistance reversal agents through inhibition of P-glycoprotein. Bioorg Med Chem 25: 1219-1226, 2017.

38. Yang Z and Zhao X: A 3D model of ovarian cancer cell lines on peptide nanofiber scaffold to explore the cell-scaffold interaction and chemotherapeutic resistance of anticancer drugs. Int $\mathrm{J}$ Nanomedicine 6: 303-310, 2011.

This work is licensed under a Creative Commons Attribution-NonCommercial-NoDerivatives 4.0 International (CC BY-NC-ND 4.0) License. 